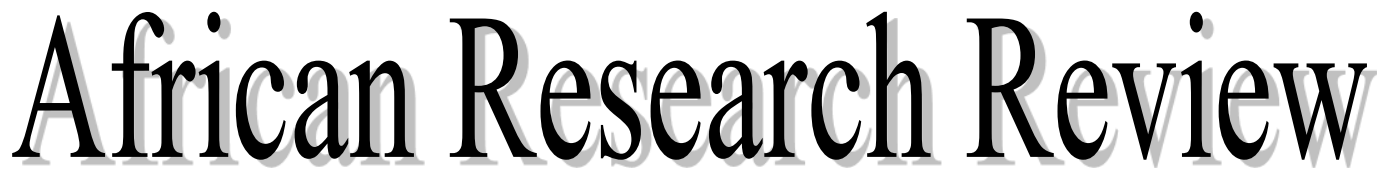

An International Multidisciplinary Journal, Ethiopia

Vol. 10(1), Serial No.40, January, 2016:257-267

ISSN 1994-9057 (Print) ISSN 2070--0083 (Online)

Doi: http://dx.doi.org/10.4314/afrrev.v10i1.20

\title{
Correlates of Bio-Psychosocial Factors on Perceived Body Image amongst Adolescents: Implications for Preventive Health Education
}

\author{
Asagba, R. B. \\ Senior Lecturer, Psychology Department \\ University of Ibadan, Ibadan \\ Oyo State, Nigeria \\ E-mail: rbasagba@gmail.com
}

\author{
Agberotimi, Samson. Femi \\ Clinical Psychologist Office, Mental Health Department, \\ Ladoke Akintola University Teaching Hospital, Ogbomoso, \\ Oyo State, Nigeria, 210271 \\ E-mail: femiagberotimi@ gmail.com \\ Phone number: +2348034891825 \\ $\&$
}
Alli, T.
Psychology Department,
University of Ibadan, Ibadan
Oyo State, Nigeria
E-mail: alli.t@yahoo.com 


\begin{abstract}
The study examined the interrelationships between a variety of measures designed to index the associations among adolescents' bio-psychosocial factors and body image. Participants were 300 students whose age range between 11 and 26 years (mean $=16.80, \mathrm{SD}=4.17)$ who completed questionnaires. The questionnaire contained measures of demographics, self-esteem, self-efficacy, food habit index, exercise, weight. Data was analyzed using correlation analysis. The results indicated that there was a positive relationship between self-esteem and perceived body image $(\mathrm{r}=.45, \mathrm{p}$ $<.01)$ and between self-efficacy and body image $(r=.22, \mathrm{p}<.01$. While a negative relationship was found between food habit index and perceived body image $(r=-.22$, $\mathrm{p}<.01)$, food habit and perceived body image $(\mathrm{r}=-.24, \mathrm{p}<.01)$ and body weight and perceived body image $(r=-.17, p<.01)$. There was no relationship between exercise and perceived body image $(r=.07, p>.05)$. The implication of these findings for preventive health education were discussed and stakeholders were advised to inculcate the essence of physical activities and balance food eating habit in their programme in order to improve the level of body image satisfaction among adolescents.
\end{abstract}

Keywords: Body image; food habit; self-esteem.

\title{
Introduction
}

The way individuals perceive self and things in the environment has both cognitive and affective components. While the cognitive component represents the mental interpretation given to the perceived object, the affective component represents the feelings that emanates from the mental interpretation of the object, which attracts a broad range of value that range from negative to positive in our mind. Although the perception of one's body can vary from day to day, individuals tend to have a relatively stable view of their body. Body image is how an adolescent perceives his/her body (Gabel and Kearney, 1998). Body image has been described as the combination of a person's psychosocial adjustment experiences, feelings and attitudes that is associated with the form, function, appearances and desirability of one's own body which is influenced by individual and environmental factors (Horgan and Maclachlan, 2004). However, a positive body image may bring about satisfaction based on one's body perception. Conversely, if a person is dissatisfied with what he/she sees, the body image is negative. Therefore, perception of body image occurs on a continuum which determines how satisfied or dissatisfied an individual is, rather than in a categorical form of whether satisfied or dissatisfied.

The term body image is a reflection of one's ability to regard parts of one's body as belonging to the self or to define the boundaries of one's own body and one's subjective, mental representation of his or her physical appearance (Thompson, 1990). Therefore, body image is constructed from self-observation, the reaction of others, and a complicated interaction of attitudes, emotions, fantasies, and experience, both 
conscious and unconscious. The importance of body image and its link with psychological well being have been supported by many studies. For instance, Thompson (1990) referred to body image dissatisfaction as body image disturbance. While Denniston, Roth and Culkroy (1992) found association of body image dissatisfaction with the incidences of depression. Also, Thompson and Altabe (1991) discovered incidences of heightened anxiety and lowered self-esteem based on one's body image perception. Similarly, (Creedon, Ray and Harkins, (2009) reported peer factors (past teasing), physical factors (BMI), specific psychological characteristics (self-esteem, independent self-construal), and family environment (independence) as significant predictors of body-image disturbance and eating problems among young adult women. All these translated to the fact that adolescents are more likely to have poor physical health due to severe dieting habit among others in an effort to have a more positive image of their body. Wald (2004) further noted that an individual's perception of his/her body image is not limited to providing a sense of 'self', but involves in how we think, act and relate to others. This can eventually lead to inability to function well in society. In this regard, adolescents may shy away from social situations and may be reluctant to form personal relationship because of the amount of time they spend in trying to achieve a better body.

It has been observed that dissatisfaction with one's body has become "a normative discontent" (Thompson, 1990). Ntim and Sarfo, (2015) were also of the opinion that the recent global advances in media technology largely accounts for the rise problems with body image that has been witnessed in the contemporary time. In today's modern culture body image is closely correlated to a drive for thinness. The inability to shed unwanted kilograms can have a drastic result on overall mood and self-confidence. As a result, body image dissatisfaction, weight concerns, eating problems, and physical attractiveness have become especially significant issues on campuses (Harris, 1995); Mintz and Betz, 1988). In the same vein, Delene and Brogowicz (1990) reported that $90 \%$ of university students in their study said that they are concerned about their body image. However, Bardone-Cone, Cass and Ford (2008), reported gender difference in factors significantly influencing body dissatisfaction, while perceived media pressure was reported for men, multiple biopsychosocial variables were more identified among women.

Body weight is an important concept that is a concern for almost everyone. Hare, et al. (2000) viewed weight gain and fat as part of normal development in adolescent, yet a significant proportion of young people today seek the cultural ideal of sliminess as it is perpetuated by Western society. This perception has conceptualized overweight/obese as a negative situation that affects all aspect of one's health with associated social and psychological problems as well as physical ones.

According to medical experts, individuals who are overweight (Body Mass Index: BMI of 25 to 29.9) may incur moderate health risks such as heart disease, 
diabetes and high blood pressure. A BMI of $30+$ is considered to be obese which is associated with increased risk of metabolized diseases and other health problems. It also increases the risk of death from any cause by 50 to 80 percent. For instance, Linda and Jess, (2004) estimated that BMI 35+ and a waist size of over 40 inches (men) and 35 inches (woman) are considered to be at especially high risk of health problems. Obesity has been identified as part of the spectrum of conditions related to disordered eating, and as a result of the increase in various problems associated with obesity, many studies have focused on the issue of body weight as it relates to body image body image and dissatisfaction (Littleton and Ollendick, 2003; Haines and Neumark-Sztainer, 2006). Relationship between increasing weight status and body dissatisfaction in adolescents has been established across different settings (Ozmen, et. al. 2007; Crow, et. al. 2006; Mirza, Davis and Yanovski 2005).

Self-efficacy is another factor influencing an adolescent's perception of body image. Bandura (1994) defined self-efficacy as individuals' beliefs and capabilities to produce designated levels of performance and exercise influence over events that affect their lives. Therefore, a high sense of efficacy enhances human accomplishments and personal well being. For instance, adolescents that have strong faith in their capabilities believe in changing what can be changed and leaving what cannot be changed. If there is anything they can change about their image and weight they make sure they work towards it in setting goals and accomplish the set goals. Conversely, adolescents who doubt their capabilities and shy away from their body image and weight feel frustrated, thus hindering them from achieving set goals. In the same vein, adolescents who have poor body image have been identified to be at a higher risk for developing low selfesteem (Desmond, et. al 2002).

Exercise is also an important determinant of body image. For instance, Sonstoem $(1984,1977)$ revealed that the majority of studies showed a significant positive relationship between self-esteem and exercise. It was concluded that regular exercise program improves physical health, enhance body image, raise physical fitness, boost feelings of self-mastery, increase social support, bolster feelings of self-control and improve physical self-efficacy.

From the foregoing, any one or combination of these factors can lead to better feelings about oneself. Parsons and Bentz (2001) called for more studies on the interaction of physical exercise and body image because the literature on body image and exercise reveals some unexpected associations. For instance (Davis and Cowles (1991) noted that although women who exercise are generally leaner, they exhibit similar or even greater degrees of body dissatisfaction than women who do not exercise. Struggling with excessive weight gain is a major problem in Nigeria today. This may drive people in search for a truly healthful weight loss solution. 
Thinness is no longer considered unattractive in contemporary society especially for women as it was in the past when it is highly desirable to be plump. In a recent study, Hatami, Taib, Djazayery, Mojani and Mejleji (2015) reported a high rate of body dissatisfaction (over 75\%) among Tehranian adolescents. They further observed a significant correlation between objectively measured weight status and body image perception and body dissatisfaction in their study participants irrespective of gender, although boys reported low level of body dissatisfaction. In addition, half of the participants reportedly perceived themselves thinner than their real weight. In another study on thinness-idealness, Thompson and Stice (2001) opined that expectations of the benefits of being extremely thin - such as social acceptance and self-esteem - are necessarily internalised alongside the thin-ideal.

The present study was designed to examine the interrelationships amongst biopsychosocial factors such as self-esteem, self-efficacy, food habit, food habit index, exercise, good habit and body weight amongst selected adolescents in Ibadan metropolis. It was hypothesized that there will be positive significant relationship between self esteem, self-efficacy, good habit, food habit index, body weight, exercise and body image. It was also hypothesized that there will be a significant relationship between age and body image.

\section{Methods}

Design: The cross-sectional survey research was adopted in this study. The independent variables were self-efficacy, self-esteem, good habit, food habit index, body weight and exercise while the dependent variable is body image.

Setting: The setting of the survey involved undergraduate students in the University of Ibadan and secondary school students within the institution in Ibadan, Oyo State, Nigeria. The participants were drawn from (1) University of Ibadan (2) International School and Abadina College. The study was situated in the Ibadan North Local Government are of Oyo State.

Participants: A total of 300 students took part in the study. Of these, 151 were males $(50.5 \%)$ and $148(49.5 \%)$ were females (one of the respondents did not indicate his/her sex). The age of the Adolescents range from 11 to 26 years (Mean = $16.80, \mathrm{SD}=4.17)$. Out of the 300 students, $128(42.7 \%)$ were undergraduate students and $172(57.3 \%)$ from both secondary schools located within the campus of university of Ibadan.

Instrument: A structured questionnaire format which comprised of six sections was used in the study:

Section A: Comprises demographic data designed to provide personal information such as age, gender, weight, height and the institution of the respondents. 
Section B: Consists of a modified version of Adanijo and Oyefeso (1986) self-esteem scale used to measure self-esteem. The 15 - item scale was originally developed by the authors. In this study reliability analysis reduced the items to 12 . The response format used by respondents was a 5 point Likerttype scale (strongly agree $=5$, to strongly disagree $=1$ ). The authors of the scale reported an alpha coefficient of .74 among undergraduates. A Cronbach alpha co-efficient of .71 was obtained in the pilot study for the 12 items. In the main study 4 weak items were deleted, which reduced the items to 8 items with a reliability coefficient of .73 obtained.

Section C: An 18 item scale was used to measure self-efficacy. The items were derived from the 30-item scale developed by Sherer, et. al. (1982). The 30 - item scale was originally developed to assess the social component of self-efficacy, from both interpersonal and intra-personal perspectives. The response format used by respondents was the 5 point Likert-type scale which range from strongly agree (5) to strongly disagree (1). The authors reported reliability coefficient alpha of .86 for the scale. A Reliability coefficient of .76 was obtained in the pilot study and .85 in the main study. In the main study 3 weak items were dropped, hence the scale was further reduced to 15 items.

Section D: Food habit and exercise were measured by a yes or no response format developed using a scale developed by O'Dea, Abraham and Heard (1996). This is a 31-item index. In this study a mean of 48.5 and S.D of 5.2 were obtained.

Section E: A 22 -item scale was developed by the researchers to measure perceived body image. The reliability coefficient of the scale obtained in the in the pilot study was .87 and a coefficient of .93 was obtained in the main study.

Section F: Body weight was measured by a 4-item body weight scale-measuring range of nine categories of males and females (Very Underweight through to Very Obese) [31]. The researchers obtained a reliability coefficient of .81 in the pilot study. In the main study, a reliability coefficient of . 78 was obtained.

Study Procedure: This study consists of three phases: the first phase involved getting permission from the management and principal officials of the schools that were used in the study. The officials were also informed of the main objective of the study and were also assured of the confidentiality of all information received, while informed consent was obtained on behalf of the students under the age of 18years. Use of carefully designed questionnaire was the major means of data collection. 
The second phase was the conduct of a pilot study carried out among the students of the University of Ibadan. The pilot study was carried out to determine the reliability of the scales used in the study as well as determine to what extent are the respondents familiar with the items on the scale. A total of 70 undergraduate and secondary school students responded to the questionnaires (self-esteem, self-efficacy, perceived body image and body weight), while twenty students responded to the food and exercise habit index.

The third phase was the main study of the research to know the extent to which biopsychosocial factors determine body image. A total of three hundred students who freely consented to participate in the study after the purpose of the study has been explained to them responded to the questionnaires. The participants were recruited from their various departments, hall of residents and classrooms. Collection of data took 2 weeks. The questionnaires were collated and scored for data analysis. The data was subjected to analysis using the SPSS 20.

\section{Results}

A zero order correlation analysis was performed on the major variables of study. The result is presented in Table 1 . As shown in Table 1 , there was a positive relationship between self-esteem and perceived body image $(r=.45, p<.01)$. Selfefficacy was positively related to perceived body image $(r=.22, p<.01)$; food habit index was negatively related to perceived body image $(\mathrm{r}=-.22, \mathrm{p}<.01)$, food habit $(\mathrm{r}$ $=-.24, \mathrm{p}<.01)$ and body weight $(\mathrm{r}=-.17, \mathrm{p}<.01)$. There was no significant relationship between exercise and perceived body image $(r=.07, \mathrm{p}>.05)$.

In addition, significant relationships were found amongst the independent variables. For instance, age was positively related to self-esteem $(r=.17, p<.01)$, food habit index $(\mathrm{r}=.29, \mathrm{p}<.01)$, exercise $(\mathrm{r}=.29, \mathrm{p}<.01)$, and food habit $(\mathrm{r}=.23, \mathrm{p}<.01)$. While, there was a positive relationship between self-esteem and self-efficacy $(r=.32$, $\mathrm{p}<.01)$. Food habit index had a significant relationship with exercise $(r=.67, p<.01)$, food habit $(\mathrm{r}=.93, \mathrm{p}<.01)$, and body weight $(\mathrm{r}=.21, \mathrm{p}<.01)$.

\section{Discussion}

In this study, self-esteem, self-efficacy, food habit, food habit index, exercise and body weight were examined as they correlate with body image. As it was reflected in our hypothesis, all the independent variables, except for exercise were positively related the dependent variable (body image). This has confirmed many previous studies with exception of the exercise which is contrary to our expectation. In line with the recommendation of Sonstroem (1977) who requested for further research on the interaction or interrelationship between physical exercise and body image because of 
the inconsistency results in the previous studies on body image and exercise, this study has been able to provide evidence to establish the relationship between perceived body image bio-psychosocial factors.

We found no significant relationship between body image and exercise in the present study. A possible explanation for this could be the fact that certain environmental and cultural factors in Nigeria do not promote regular physical exercise practice. An average Nigerian citizen is preoccupied with different daily activities in a bid to get ends meet, thus limit the chance of exercising the body for fitness.

As predicted, a positive relationship was found between self-esteem and body image. The result of this study supports the work of Desmond, et. al. (2002) in which they reported that adolescents who have a poor body image are at higher risk for low self-esteem. The results of this study also supports the previous works of (Gabel and Kearney, 1998); Thompson and Altabe, 1991); Creedon et. al. (2009) and Hatami et. al. (2015). However, our finding is in contrast to the work of Davis and Cowles (1991) who investigated intergenerational and cross-cultural aspects of body weight satisfaction in 103 female Yoruba students, 48 adult women in Nigeria and 68 Nigerian women living in Britain. Much discrepancy between current and desired BMI was reported by the students in the study, unlike what was obtainable in the adult population. This observation is however in contrast to what was observed in the Western population where neither adolescent nor adult group showed a marked overall dissatisfaction with their current BMI. This therefore calls for further research.

Also from our results, individuals who reported dysfunctional body image were also shown to have negative eating habit, and poor perception of their body weight. This finding is consistent with previous works of (Hatami et. al. 2015). Similarly, Creedon, et. al. (2009) reported a predictive influence of physical factors (BMI) on body-image disturbance among young adult women. In addition, a recent study by Ntim and Sarfo, (2015) recent increase in problems of body image disturbance was attributed to recent global advances in media technology which set people on the course of pursuing an 'ideal body image'.

Condition of homogeneity of the study sample was regarded as a limitation of the present study which could have influenced the direction of the findings. Further research is needed among the population across different life span. However, this study is unique in the sense that it raised some issues where few researchers had dwelled on which has also laid the foundation for further research.

\section{Conclusion}

This study evaluated the bio-psychosocial correlates of body image among adolescents in Nigeria. We found significant relationships between the variables of interest except for exercise which called for further study. All the bio-psychosocial 
factors examined are needed to be considered in health programmes in all relevant institutions in Nigeria because they constitute important factors in maintaining people's holistic health as well psychological wellbeing which most health care providers often neglect in Nigeria.

\section{References}

Adanijo, I. B. \& Oyefeso, A. O. (1986). Developing self-report scale of self-esteem. A Paper presented at the 3rd Annual conference of the Nigerian Psychological Association. Nsukka.

Bandura, A. (1994). Self-efficacy. In V. S. Ramachaudran (Ed.), Encyclopedia of human behaviour, 5, 71-89. New York: Academic Press.

Bardone-Cone, A. M., Cass, K. M., \& Ford, J. A. (2008). Examining body dissatisfaction in young men within a biopsychosocial framework. Body Image 5, 183-194

Creedon, M. T., Ray, S. \& Harkins, D. A. (2009). Peer teasing, body-image and eating problems among women. American journal of psychological research, 5 (1), 111 $-130$

Crow. S., Eisenberg, M. E., Story, M. \& Neumark-Sztainer, D. (2006). Psychosocial and behavioural correlates of dieting among overweight and nonoverweight adolescents. J Adolesc Health, 38, 569-574.

Davis, C. \& Cowles, M. (1991). Body image and exercise: A study of relationships and comparisons between physically active men and women. Sex Roles, 25, 33 - 44.

Delene, L. \& Brogowicz, A. (1990). Student health care needs, attitudes and behaviour: Marketing implication for college health centers. Journal of American College Health, 38, $157-164$.

Denniston, G., Roth, D \& Culkroy, F. (1992). Dysphonia and body image among college women. The International Journal of Eating Disorders, 12, 449 - 452.

Desmond, S.M., Price, J.H., Gray, N. \& O'Connell, J.K. (2002). The etiology of adolescents' perceptions of their weight. Journal of Youth and Adolescence, 15, $461-474$.

Gabel, V.H. \& Kearney, K. (1998). Promoting reasonable perspectives of body weight. Issues for school Counselors Professional School Counselling 1 (5), 32 - 35.

Haines, J. \& Neumark-Sztainer, D. (2006). Prevention of obesity and eating disorders: A consideration of shared risk factors. Health Educ Res, 21, 770-782.

Hare, S.W., Price, J.H., Flym, M. G. \& King, K.A. (2000). Attitudes and perceptions of fitness professionally regarding Obesity. Journal of Community Health 25, 5- 20.

Harris, S. (1995). Body image attitudes and psychosocial development of College Women. Journal of Psychology, 129, 315 - 330. 
Hatami, M., Taib, M. N. M., Djazayery, A., Mojani S. M. and Mejlej, H. F. (2015). Relationship between body image, body dissatisfaction and weight status in Iranian adolescents. Archives of Obesity, 1:1. Retrieved from http://www.vipoa.org/obesity

Horgan, O. \& Maclachlan. M. (2004). Disability and Rehabilitation: Psychosocial adjustment to lower-limb amputation. 26 (14/15). P 837-850. http://web.ebscohost.com.ezproxy.turkuamk.fi/ehost/? Retrieved on 31.08.2015

Linda, B. \& Jess, F. (2004). Health Psychology. An Introduction to Behaviour and Health Fifth (Ed) 15: 428.

Littleton, H. L. \& Ollendick, T. (2003). Negative body image and disordered eating behavior in children and adolescents: what places youth at risk and how can these problems be prevented? Clin Child \& Fam. Psychol Rev, 6, 51-66.

Mintz, L. \& Betz, N. (1988). Prevalence and Correlates of Eating Disordered behaviour among Undergraduate Women. Journal of Counseling Psychology, 35, 463 - 471.

Mirza, N.M., Davis, D., \& Yanovski, J.A. (2005). Body dissatisfaction, self-esteem, and overweight among inner-city Hispanic children and adolescents. J Adolesc Health, 36, 267.e16-267.e20

Ntim, C. N. \& Sarfo, J. O. (2015). Body image and eating disorders among female students: A pilot nutritional psychology study in Ghana. Journal of Advocacy, Research and Education, 2 (1), 54 - 57.

O'Dea, J., Abraham, S. \& Heard, R. (1996). Food habits, body image and weight control practices of young male and female adolescents. Australian Journal of Nutrition and Dietetics, 53, 32-38.

Ozmen, D., Ozmen, E., Ergin, D., Cetinkaya, A.C., Sen, N., Dundar, P.E., \& Taskin, E.O. (2007). The association of self-esteem, depression and body satisfaction with obesity among Turkish adolescents. BMC Public Health, 7:80.

Parsons, E.M. \& Bentz, NE (2001). The relationship between participation in sports and physical activity to body objectification instrumentality, locus of control among young women. Psychology of Women Quarterly. 125, 2.

Sherer, M., Maddux, J. E., Mercandante, B., Prentice-Dunn, S., Jacobs, B., \& Rogers, R. W. (1982). The Self-Efficacy Scale: Construction and validation. Psychological Reports, 51, 663-671.

Sonstoem, R.J. (1984). Exercise and self-esteem. Exercise and sport science review. 12, 123-155.

Sonstroem, R.J. (1977). Physical Activity and Self-esteem in W.P. Morgan (Ed.) Physical Activity and Mental Health pp.129-143. Washington D.C. Taylor \& Finance. 
Thompson, J. K., \& Stice, E. (2001). Thin-ideal internalization: Mounting evidence for a new risk factor for body-image disturbance and eating pathology. Current Directions in Psychological Science, 10(5), 181-183.

Thompson, J. K. \& Altabe, M. D. (1991). Psychometric qualities of the Figure Rating Scale. International Journal of Eating Disorders, 10, 615 - 619.

Thompson, J. K. (1990). Body image disturbance: Assessment and treatment. Elinsford, New York: Pergamon.

Wald, J. (2004). Psychological factors in work-related amputation: Consideration for rehabilitation counsellors. Journal of rehabilitation, 70(4) 6-15. http://web.ebscohost.com.ezproxy.turkuamk.fi/ehost/pdf Retrieved on 31.08.2015

Table 1: Correlation Matrix showing the Inter-correlations among variables of interest

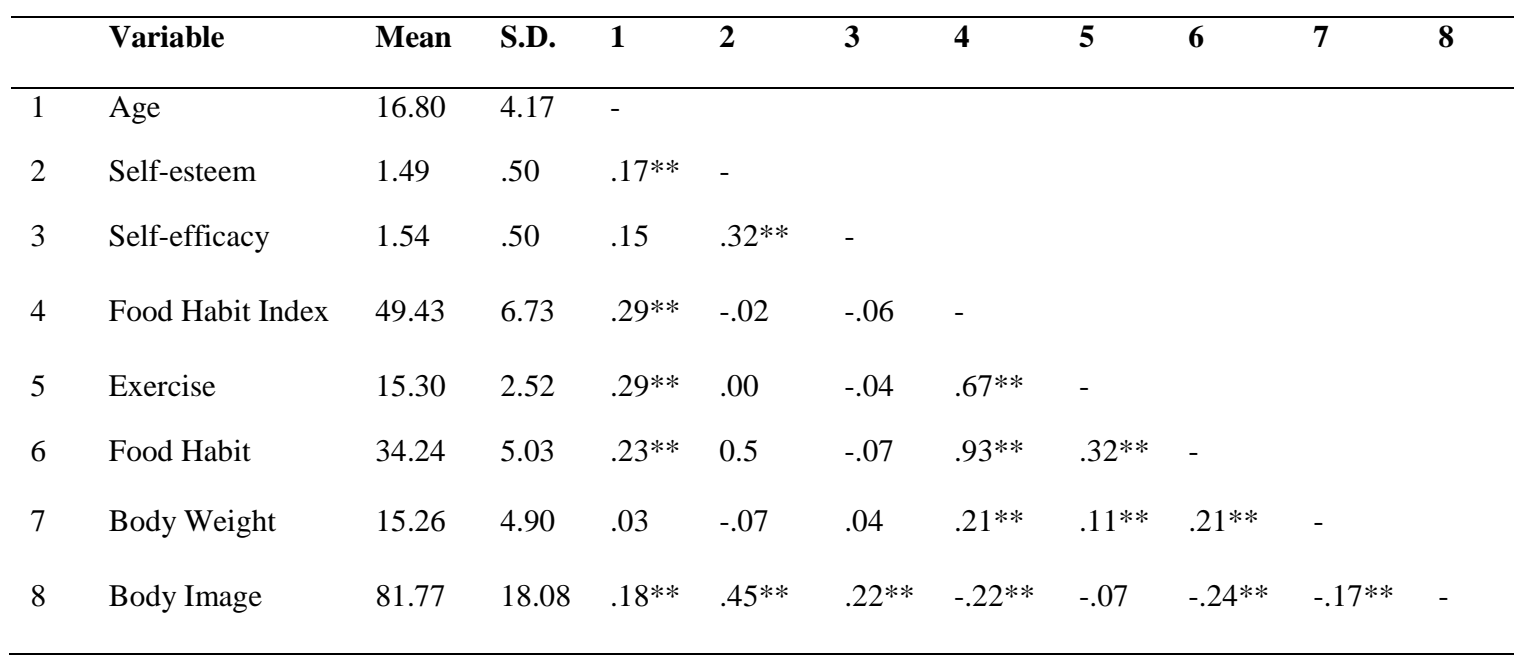

$* *$ Correlation is significant at the 0.01 level

* Correlation is significant at the 0.05 level

Abbreviations: S.D. - standard deviation 